\title{
Prevalence and outcomes of persistent pulmonary hypertension of the newborn in a neonatal unit, Mankweng Hospital, Limpopo Province, South Africa
}

\author{
M J Nchabeleng, ${ }^{1}$ MMed (Paed), HIV Man Dipl (SA); M H K Hamese, ${ }^{1}$ FC Paed (SA); T S Ntuli, ${ }^{2,3} \mathrm{PhD}$ \\ ${ }^{1}$ Department of Paediatrics, University of Limpopo, Sovenga, South Africa \\ ${ }^{2}$ Department of Public Health, University of Limpopo, Sovenga, South Africa \\ ${ }^{3}$ Department of Statistics/Operations Research, Sefako Makgatho Health Sciences University, Pretoria, South Africa
}

Corresponding author: T S Ntuli (tsntuli@hotmail.com)

\begin{abstract}
Background. Persistent pulmonary hypertension of the newborn (PPHN) is a condition of high pulmonary arterial pressures leading to hypoxaemia and continued shunting of blood across fetal channels as a result of failure of circulatory transition at birth.

Objective. To determine the prevalence and outcomes of PPHN at Mankweng Hospital, Limpopo Province, South Africa.

Methods. A retrospective descriptive review of patients' files from January 2015 to December 2017 was conducted. PPHN was diagnosed on echocardiogram.

Results. During the 3-year period of the study, a total of 6776 neonates were admitted to the neonatal unit, of whom $0.76 \%$ ( $n=52$ ) were diagnosed with PPHN. Of these, 98\% $(n=51)$ had complete information in their medical records and were further analysed. Slightly more than half $(53 \%)$ were males, $59 \%$ were delivered by caesarean section, $94 \%$ had gestational age $\geq 37$ weeks, and $39 \%$ and $14 \%$ had Apgar scores of $<6$ at 1 minute and 5 minutes, respectively. Most neonates (72\%) had meconium aspiration as the single risk factor or in combination with other conditions. Nearly half (45.1\%) of the neonates with PPHN did not survive. Gender, mode of delivery, and Apgar score were each correlated with PPHN mortality and they all showed no statistically significant association. A significantly higher proportion of non-survivors received inotropic support than survivors $(p<0.05)$.

Conclusions. The prevalence of PPHN was found to be lower than in other low- and middle-income countries; nonetheless, the all-cause mortality rate is significantly high. The commonest aetiology of PPHN is meconium aspiration syndrome as a single underlying risk factor, and in combination with other conditions. Most neonates who needed inotropic support died.
\end{abstract}

S Afr J Child Health 2021;15(2):103-107. https://doi.org/10.7196/SAJCH.2021.v15.i2.1773

Persistent pulmonary hypertension of the newborn (PPHN) is a consequence of the failure of normal circulatory transition that occurs at birth, resulting in sustained elevated pulmonary arterial pressures with shunting of non-oxygenated blood across the ductus arteriosus (DA) and foramen ovale (FO). This further results in severe hypoxaemia, and it may eventually lead to lifethreatening circulatory failure. ${ }^{[1]}$ The prevalence of PPHN differs geographically. It is lower than $1 \%$ in high-income countries, ${ }^{[2]}$ whereas in low- and middle-income countries it ranges between $1 \%$ and $5 \%{ }^{[3,4]}$ The commonest aetiologies of PPHN are meconium aspiration syndrome (MAS), respiratory distress syndrome (RDS) and pneumonia. ${ }^{[4-8]}$ There are various risk factors associated with PPHN such as term and post-term neonates, ${ }^{[3,5,7]}$ male gender, ${ }^{[3,9,10]}$ female gender, ${ }^{[2,7]}$ caesarean section (CS) delivery, ${ }^{[3,4,9-11]}$ intra-uterine growth restriction, ${ }^{[12]}$ maternal diabetes ${ }^{[13]}$ and low Apgar score. ${ }^{[7]}$

Despite advances in the management of PPHN, which includes improving oxygenation by optimising lung volume by ventilatory techniques, surfactant and administering pulmonary vasodilator agents, ${ }^{[14-16]}$ the morbidity and mortality associated with this condition remains a challenge, ranging from $20 \%$ to $50 \%{ }^{[3,4,8,17,18]}$ In South Africa (SA), earlier studies reported PPHN mortality rate between $30 \%$ and $50 \% \cdot{ }^{[7,19,20]}$ To the best of our knowledge after a thorough literature review, no study on the prevalence, mortality, and underlying causes of PPHN has been performed in this rural province of SA. Given the paucity of epidemiological information about PPHN in this region, this study was conducted with the aim to determine the prevalence and outcomes of PPHN at Mankweng Hospital, Limpopo Province, SA.

\section{Method}

This was a retrospective descriptive study based on a review of the medical records of neonates admitted to the neonatal unit of Mankweng Hospital, the only tertiary referral hospital with intensive care services in the Limpopo Province. The data for this study were collected over a 3-year period from January 2015 to December 2017. Ethics approval to conduct the study was obtained from the University of Limpopo Ethics Committee (ref. no. TREC/137/2018: PG), and anonymity and confidentiality of personal patient information were protected by using allocated unique numbers. The neonatal unit is a 60-bed unit with 9 beds for intensive care, 9 beds for high care, a nursery with 30 beds, and 12 kangaroo-mother-care beds. The unit registers a total admission of 2000 patients per annum.

A consecutive sample of neonates paired with their mothers was selected for the study. Data were collected using a data collection form designed for the study. The neonatal unit discharge register, which is updated daily, was used as the starting point to collate a list of neonates admitted during the study period, after which the relevant medical records were retrieved. Using the register and patient files, 
the following data were collected: mode of delivery, gestational age (GA) at delivery, gender of the baby, date of birth, Apgar scores (at 1 and 5 minute/s), underlying risk factors of PPHN, treatment received and outcomes. The diagnosis of MAS was made on the basis of typical chest radiographic changes of a neonate born with meconiumcontaining amniotic fluid, and pneumonia is diagnosed in a newborn by means of a chest radiograph and clinical signs of pneumonia. Statistical analyses were performed using the statistical programme STATA version 10.0 (StataCorp., USA). Comparisons between survivors and non-survivors were performed using Fisher's exact test and a $p$-value of $\leq 0.05$ was considered significant.

\section{Results}

A total of 6776 neonates were admitted to the neonatal unit during the 3-year period, of whom $0.76 \%$ ( $n=52)$ were diagnosed with PPHN. Of these, $98 \%(n=51)$ had complete information in their medical records and were included in the study for further analysis (Table 1). Slightly more than half (53\%) were males, $59 \%$ were delivered by CS and $94 \%$ had a gestational age $(\mathrm{GA}) \geq 37$ weeks. An Apgar score of $<6$ at 1 minute and 5 minutes was seen in $39 \%$ and $14 \%$, respectively.

Table 1. Demographic characteristics of neonates with PPHN $(N=51)$

\begin{tabular}{ll}
\hline \multicolumn{2}{l}{$\boldsymbol{n}(\%)$} \\
\hline Sex & \\
Male & $27(53)$ \\
Female & $24(47)$ \\
Mode of delivery & \\
$\quad$ Vaginal & $21(41)$ \\
Caesarean & $30(59)$ \\
Gestational age (weeks) & \\
$<37$ & $3(6)$ \\
$37-42$ & $45(88)$ \\
$>42$ & $3(6)$ \\
Apgar score $<6$ at 1 minute & $20(39)$ \\
Apgar score $<6$ at 5 minutes & $7(14)$
\end{tabular}

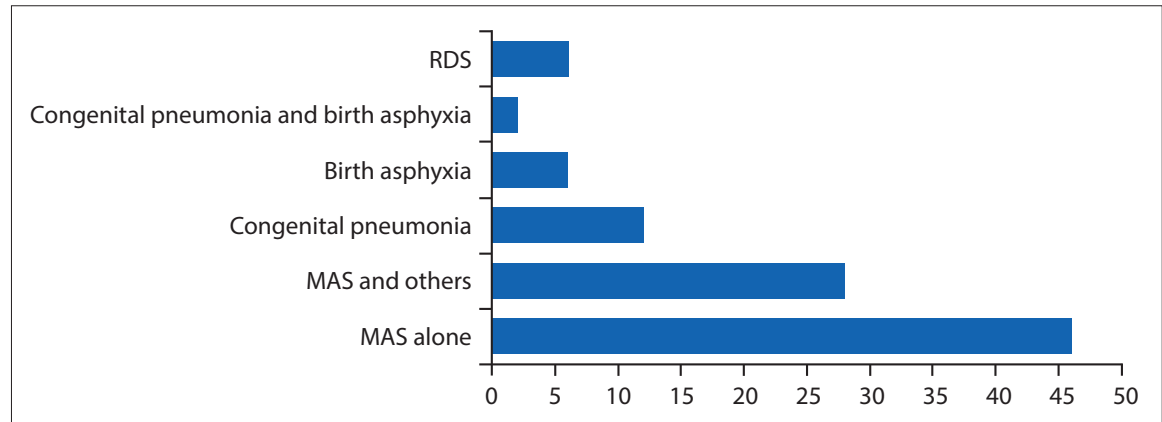

Fig. 1. Distribution of underlying causes of PPHN (RDS = respiratory distress syndrome;

PPHN = persistent pulmonary hypertension of the newborn; others $=$ congenital pneumonia and birth asphyxia; $M A S=$ meconium aspiration syndrome.)

Fig. 1 illustrates the underlying risk factors present in neonates with PPHN. Nearly half (46\%) of the neonates had MAS as the single underlying risk factor of PPHN, followed by congenital pneumonia and birth asphyxia accounting for $12 \%$ and $6 \%$ of the single risk factors, respectively. Some of the neonates had multiple underlying risk factors such as 28\% MAS and other diseases (i.e. 20\% birth asphyxia; 6\% congenital pneumonia and $2 \%$ congenital pneumonia/birth asphyxia) and RDS and other conditions 6\% i.e. $2 \%$ congenital pneumonia; $2 \%$ birth asphyxia and $2 \%$ congenital pneumonia/ birth asphyxia).

Nearly half $(45 \%)$ of the neonates with PPHN did not survive. As shown in Table 2 , there was no statistically significant difference in the mortality rates of males and females. The difference in mortality risk among neonates delivered by CS was not statistically significant $(p>0.05)$. There was a significant relationship between mortality risk of neonates with PPHN and $\mathrm{GA}(p<0.05)$

Regarding clinical intervention, mechanical ventilation was administered to $98 \%$ of the neonates with PPHN, whereas sildenafil was administered to $96 \%$ of the babies but there was no 
Table 2. Neonatal factors associated with PPHN mortality

\begin{tabular}{|c|c|c|c|c|}
\hline & $N(\%)$ & Survivor, $n(\%)$ & Non-survivor, $n(\%)$ & $p$-value \\
\hline \multicolumn{5}{|l|}{ Sex } \\
\hline Male & $27(53)$ & $17(61)$ & $10(43)$ & \multirow{2}{*}{0.267} \\
\hline Female & $24(47)$ & $11(39)$ & $13(57)$ & \\
\hline \multicolumn{5}{|c|}{ Mode of delivery } \\
\hline Vaginal & $21(41)$ & $12(43)$ & $9(39)$ & \multirow{2}{*}{1.000} \\
\hline Caesarean & $30(59)$ & $16(57)$ & $14(61)$ & \\
\hline \multicolumn{5}{|c|}{ Gestational age (weeks) } \\
\hline$<37$ & $3(6)$ & 0 & $3(13)$ & \multirow{3}{*}{0.038} \\
\hline $37-42$ & $45(88)$ & $25(89)$ & $20(87)$ & \\
\hline$>42$ & $3(6)$ & $3(11)$ & 0 & \\
\hline \multicolumn{5}{|c|}{ Apgar score at 1 minute } \\
\hline$<6$ & $20(39)$ & $8(29)$ & $12(52)$ & \multirow{2}{*}{0.149} \\
\hline$\geq 6$ & $31(61)$ & $20(61)$ & $11(48)$ & \\
\hline \multicolumn{5}{|c|}{ Apgar score at 5 minutes } \\
\hline$<6$ & $7(14)$ & $3(43)$ & $4(57)$ & \multirow{2}{*}{0.687} \\
\hline$\geq 6$ & $44(86)$ & $25(57)$ & $19(43)$ & \\
\hline \multicolumn{5}{|c|}{ Clinical intervention } \\
\hline Inotropes & $30(59)$ & $11(39)$ & $19(83)$ & $<0.001$ \\
\hline
\end{tabular}

The management of PPHN remains a serious challenge, with a high mortality rate reported in low- and middle-income countries. Mortality rates directly or indirectly related to PPHN were found to be $25 \%$ in Egypt, ${ }^{[4]} 29 \%$ in India, ${ }^{[8]} 42 \%$ in Mexico ${ }^{[17]}$ and $32 \%$ in Portugal. ${ }^{[3]}$ A multicentre study conducted in Asian countries (Japan, Kuwait, India, Pakistan, Singapore, and Thailand) found a mortality rate of $20.6 \% .^{[18]}$ In SA, several studies reported PPHN mortality rates ranging between $30 \%$ and $50 \%{ }^{[7,19,20]}$ Our finding is consistent with these reports, as we found that nearly half (45\%) of the neonates with PPHN did not survive. We also attempted to evaluate whether there was any difference between the survivors and non-survivors in relation to demographics and treatment modalities. In line with previous studies, ${ }^{[19]}$ a need for inotropic therapy was associated with poor outcome. This is likely because in our study setting, neonates who received inotropes may already have had poor prognosis. Given resource limitations in our setting, several practical measures can be considered to reduce this high mortality. They include close antenatal monitoring and improved perinatal management of patients at risk, with improved neonatal resuscitation skills to reduce the incidence of meconium aspiration and birth asphyxia. The results of our study revealed higher mortality rates among neonates with lower GA similar to other studies. ${ }^{[7,18]}$ A retrospective study conducted in a referral centre in India found that the mean Apgar score at 5 minutes was significantly less in non-survivors. ${ }^{[8]}$ Similarly, in our study, the mortality rate was high in the neonates, with a 5-minute Apgar score of $<6$ but the result was not statistically significant.

\section{Study limitations}

The above findings must be considered in the context of the following limitations. As with retrospective studies, any missing data from patient files affect the reliability of the data. There was some incompleteness of notes regarding the mothers' pregnancy and data on the infants: maternal illness, resuscitation post delivery, postnatal age, duration of mechanical ventilation and whether the baby was in/out-born. Some of the cases could have been missed because the neonatal unit register was used as a starting point of data collection and some information might not have been entered. This might have under- or overestimated the prevalence of PPHN. Another limitation is that the study was based on results from a single centre and may not have been representative of a wider profile of PPHN.

\section{Conclusions}

The prevalence of PPHN in Mankweng Hospital, a rural tertiary hospital in Limpopo Province, SA, is lower but the all-cause mortality rate is as high as those reported from other resourcelimited facilities. The commonest aetiology of PPHN is MAS as a single underlying risk factor, and in combination with other conditions. Early diagnosis and prompt treatment for PPHN is essential to avoid the need for inotropic therapy, because neonates who needed inotropic support were found to have high mortality. Future studies on this condition should involve multiple neonatal centres.

\section{Declaration. None.}

Acknowledgements. The authors acknowledge the management of the hospital for giving us permission to conduct this study. We would also like to extend our appreciation to Andrew Scholtz for proofreading and editing the manuscript.

Author contributions. MJN contributed to conceptualisation, data collection and writing of the manuscript. TSN and MHK participated in the data analysis and critically revised the manuscript. All authors reviewed and approved the final manuscript.

\section{Funding. None.}

Conflicts of interest. None.

1. Lloyd LG, Smith J. The management of persistent pulmonary hypertension of the newborn: A review. S Afr J Child Health 2016;10(4):194-198. https://doi. org/10.7196/SAJCH.2016.v10i4.1145

2. Steurer MA, Jelliffe-Pawlowski LL, Baer RJ, Partridge JC, Rogers EE, Keller RL. Persistent pulmonary hypertension of the newborn in late preterm and term infants in California. Pediatrics 2017;139(1):e20161165. https://doi. org/10.1542/peds.2016-1165.

3. Rocha G, Baptista MJ, Guimarães H. Persistent pulmonary hypertension of non-cardiac cause in a neonatal intensive care unit. Pulm Med 2012;818971. https://doi.org/10.1155/2012/818971 
4. Mohsen AH, Amin AS. Risk factors and outcomes of persistent pulmonary hypertension of the newborn in neonatal intensive care unit of Al-Minya University Hospital in Egypt. J Clin Neonatol 2013;2(2):78-82. https://doi. org/10.4103/2249-4847.116406

5. Konduri GG, Kim UO. Advances in the diagnosis and management of persistent pulmonary hypertension of the newborn. Pediatr Clin N Am 2009;56:579-600. https://doi.org/10.1016/j.pcl.2009.04.004

6. Choudhary M, Meena MK, Chhangani N, Sharma D, Choudhary JS, Choudhary SK. To study prevalence of persistent pulmonary hypertension in newborn with meconium aspiration syndrome in western Rajasthan, India: A prospective observational study. J Matern Fetal Neonatal Med 2016;29(2):324-327. prospective observational study. J Matern Fetal Ne
https://doi.org/10.3109/14767058.2014.1000296

7. Harerimana I, Ballot DE, Cooper PA. Retrospective review of neonates with persistent pulmonary hypertension of the newborn at Charlotte Maxeke Johannesburg Academic Hospital. S Afr J Child Health 2018;12(1):29-33. https://doi.org/10.7196/SAJCH.2018.v12i1.1245

8. Sardar S, Pal S, Mishra R. A retrospective study on the profile of persistent pulmonary hypertension of newborn in a tertiary care unit of Eastern India. J Clin Neonatol 2020;9:18-26. https//:doi.org/10.4103/jcn.JCN_68_19

9. Roofthooft MTR, Elema A, Bergman KA, Berger RMF. Patient characteristics in persistent pulmonary hypertension of the newborn. Pulm Med 2011:85815. https//:doi.org/10.1155/2011/858154

10. Razzaq A, Quddusi AI, Nizami N. Risk factors and mortality among newborns with persistent pulmonary hypertension. Pak J Med Sci 2013;29(5):1099-1104. https://doi.org/10.12669/pjms.295.3728

11. Bakheet MA, Metwalley KA, Abdel-raheem AS. Evaluation of persistent pulmonary hypertension of the newborn (PPHN) in Upper Egypt. Egyptian Pediatric Association Gazette 2013;61(3):96-99.

12. Dargaville A, Copnell AB, Mills JF, et al. Randomised controlled trial of lung lavage with dilute surfactant for meconium aspiration syndrome. J Pediatr 2011;158:383-389. https//:doi.org/10.1016/j.jpeds.2010.08.044
13. Shu LP, Zhang RH, Cai YH, Zhou JB, Yang JK, Qi L. Maternal diabetes mellitus and persistent pulmonary hypertension of the newborn: Accumulated evidence from observational studies. Can J Diabetes 2020;44(4):327-334.. https://doi. org/10.1016/j.jcjd.2019.10.002

14. Bendapudi P, Rao GG, Greenough A. Diagnosis and management of persistent pulmonary hypertension of the newborn. Paediatr Respir Rev 2015;16(3):157 161. https//:doi.org/10.1016/j.prrv.2015.02.001

15. Nair J, Lakshminrusimha S. Update on PPHN: Mechanisms and treatment. Semin Perinatol 2014;38(2):78-91. https://doi.org/10.1053/j.semperi.2013.11.004

16. Sharma V, Berkelhamer SK, Lakshminrusimha S. Persistent pulmonary hypertension of the newborn. Matern Health Neonatol Perinatol BMC 2015;1(14):1-18

17. Ortiz MI, Esteves-Castillo R, Bautista-Rivas MM, Romo-Hernández G, LópezCadena JM, Copca-García JA. Prevalence and treatment of persistent pulmonary of the new born in a Mexican pediatric hospital. Proc West Pharmacol Soc 2010;53:39-41.

18. Nakwan N, Jain S, Kumar K, et al. An Asian multicenter retrospective study on persistent pulmonary hypertension of the newborn: Incidence, etiology, diagnosis, treatment and outcome. J Matern Fetal Neonatal Med 2018;14:1-11. https://doi.org/10.1080/14767058.2018.1536740.

19. Smith J, Kirsten GF. Persistent pulmonary hypertension of the neonate in a developing country - does extracorporeal membrane oxygenation have a role to play? S Afr Med J 1993;83:742-745.

20. Velaphi S, van Kwawegen AV. Meconium aspiration syndrome requiring assisted ventilation: Perspective in a setting with limited resources. J Perinatol 2008;28(Suppl 3):S36-S42. https://doi.org/10.1038/jp.2008.155

Accepted 22 January 2021. 